\title{
Membrane Transport Mechanisms of Mizoribine in the Rat Intestine and Human Epithelial LS180 Cells
}

\author{
Kazuya Ishida, Mari TakaAi, Ayano Yotsutani, Masato Taguchi, and Yukiya Hashimoto* \\ Graduate School of Medicine and Pharmaceutical Sciences, University of Toyama; 2630 Sugitani, Toyama 930-0194, \\ Japan. Received August 18, 2008; accepted January 30, 2009; published online February 2, 2009
}

\begin{abstract}
The aim of the present study was to characterize membrane transport mechanisms of mizoribine in the intestinal epithelial cells. We evaluated the contribution of $\mathrm{Na}^{+}$-dependent and -independent membrane transporters to mizoribine absorption in the rat intestine using an in situ closed loop method. In addition, we evaluated the effects of structurally related compounds, extracellular $\mathrm{Na}^{+}$concentrations, and an inhibitor of $\mathrm{Na}^{+}-$ independent equilibrative nucleoside transporter, nitrobenzylmercaptopurine ribonucleoside (NBMPR), on the uptake of mizoribine in human intestinal epithelial LS180 cells. In the presence and also absence of $\mathrm{Na}^{+}$in rat intestinal loops, more than $60 \%$ of the administered dose $(50 \mu \mathrm{g}$ at the concentration of $100 \mu \mathrm{g} / \mathrm{ml}=386 \mu \mathrm{M})$ of mizoribine was absorbed in $40 \mathrm{~min}$. In the LS180 cells, ribavirin and inosine reduced the uptake of $400 \mu \mathrm{M}$ mizoribine with the increasing concentrations (from 5 to $50 \mathrm{~mm}$ ) of the inhibitors. The cellular uptake of mizoribine in the absence of extracellular $\mathrm{Na}^{+}$decreased to $72.7 \%$ of the uptake in the presence of extracellular $\mathrm{Na}^{+}$, whereas $100 \mu \mathrm{M}$ NBMPR decreased the uptake of mizoribine markedly to $34.7 \%$ of that without NBMPR. These findings suggest that $\mathrm{Na}^{+}$-independent nucleoside transporters are largely responsible for absorption of mizoribine in the intestine.
\end{abstract}

Key words mizoribine; intestinal absorption; nucleoside transporter; LS180 cell

Mizoribine is an orally available immunosuppressive agent, which has been on the market since 1984 in Japan for the prevention of rejection in renal transplantation. ${ }^{1)}$ In contrast to other immunosuppressive agents (e.g., azathioprine), mizoribine has been shown in animal experiments to lack oncogenicity and exhibited a clinically low incidence of severe adverse drug reactions (such as myelosuppression and hepatotoxicity), making it useful in long-term immunosuppression therapy. ${ }^{2)}$ Orally administered mizoribine is absorbed rapidly despite its hydrophilic property; therefore, specific membrane transporters can be responsible for the intestinal absorption of the drug. ${ }^{3)}$

Concentrative nucleoside transporter (CNT) 1 and CNT2 are $\mathrm{Na}^{+}$-dependent, and the movement of nucleoside regardless of its concentration gradient is coupled to that of the sodium ion. ${ }^{4,5)}$ CNT1 and CNT2 are localized on the apical side of enterocytes, and these transporters differ in their substrate specificities: CNT1 transports pyrimidine-nucleoside (e.g., thymidine) preferentially, whereas CNT2 transports purine-nucleoside (e.g., inosine) preferentially. ${ }^{4-6)}$ Okada et $a l$. evaluated the intestinal absorption of mizoribine using the rat intestinal closed loop. ${ }^{7)}$ Inosine inhibited the absorption of mizoribine in the rat intestinal loop; therefore, they thought that the nucleoside transporter was involved in the intestinal absorption of mizoribine in rats, and that CNT2 was a plausible candidate responsible for apical uptake of the drug in intestinal epithelial cells. ${ }^{7}$ On the other hand, Mori et $a l$. investigated the effect of thymidine on the intestinal absorption of mizoribine in rats. ${ }^{8)}$ Thymidine, as well as inosine and ribavirin, decreased the intestinal absorption of mizoribine; therefore, they thought that intestinal absorption of mizoribine was mediated by CNT1 as well as CNT2. ${ }^{8)}$

Equilibrative nucleoside transporter (ENT) 1 and ENT2 are $\mathrm{Na}^{+}$-independent, and mediate nucleoside transport in both directions depending on the nucleoside concentration gradient. ${ }^{5,9)}$ ENT1 and ENT2 transport both pyrimidineand purine-nucleoside, and they are inhibited by 6-[(4-nitro- benzyl)-thio]-9- $\beta$-D-ribofuranosyl-purine (NBMPR) ${ }^{5,9)}$ Recently, Govindarajan et al. investigated the expression of nucleoside transporters in the human intestine, liver, kidney, and placenta. ${ }^{6}$ In the human intestine, immunohistochemical analysis showed the presence of ENT1 and ENT2 protein staining in the crypt regions. The intensity seemed higher than the respective immunoreactivity observed in the enterocytes in the same histological section on the same slide. In addition, a certain degree of ENT1 and ENT2 staining was always observed in all the villi cells, with almost equal intensity at the apical and basolateral side of the enterocytes. ${ }^{6}$ On the other hand, it is still unclear whether ENTs are involved in the apical membrane transport of mizoribine in the intestinal epithelial cells.

In the present study, we evaluated the contribution of $\mathrm{Na}^{+}-$ dependent and -independent nucleoside transport to rat intestinal absorption of mizoribine using in situ closed loop methods. In addition, we performed pharmacokinetic analysis of cellular uptake of mizoribine in human intestinal epithelial LS180 cells. ${ }^{10-13)}$ We further evaluated the effects of structurally related compounds, extracellular $\mathrm{Na}^{+}$concentrations, and NBMPR on the cellular uptake of mizoribine in LS180 cells.

\section{MATERIALS AND METHODS}

Materials Mizoribine and $\left[{ }^{14} \mathrm{C}\right]$ mizoribine $(12.9 \mathrm{mCi} /$ mmol) were kindly donated by Asahi Kasei Pharma (Tokyo, Japan). $\left[{ }^{3} \mathrm{H}\right]$ Mannitol was purchased from Moravec Biochemicals Inc. (Brea, CA, U.S.A). Ribavirin was obtained from MP Biochemicals, LLC. (Illkirch, France). Inosine and NBMPR were purchased from Sigma-Aldrich (St. Louis, MO, U.S.A). All other chemicals were of the highest purity available.

Animals Male Wistar rats $(190-230 \mathrm{~g})$ were purchased from Japan SLC Inc. (Hamamatsu, Japan). Rats were housed in a temperature- and humidity-controlled room with free ac- 
cess to water and standard rat chow. All experiments were performed in accordance with the Guidelines for Animal Experiments of University of Toyama.

LS180 Cells LS180 cells at passage 38 were obtained from the American Type Culture Collection (Manassas, VA, U.S.A.). LS180 cells were seeded at a density of $5 \times 10^{5}$ cells $/ \mathrm{cm}^{2}$ on a $3.8 \mathrm{~cm}^{2}$ plastic dish using a Falcon ${ }^{\circledR}$ multiwell $^{\mathrm{TM}}$ plate (BD Bioscience, Bedford, MA, U.S.A.). They were maintained with Dulbecco's modified Eagle's medium supplemented with $10 \%$ fetal bovine serum (Biowest, Nuallé, France) in atmosphere of $5 \% \mathrm{CO}_{2}-95 \%$ air at $37^{\circ} \mathrm{C}$ for 7 d. $^{12,13)}$ All experiments were carried out between passages $55-66$.

Intestinal Absorption of Mizoribine in Rats Rats were fasted for $20 \mathrm{~h}$ with free access to water before the subsequent experiment. The rat was anesthetized with $50 \mathrm{mg} / \mathrm{kg}$ sodium pentobarbital, and body temperature was maintained with appropriate heating lamps. The abdominal cavity was opened, and silicon tubes were inserted at the end of the pylorus and the middle of the small intestine. The lumen of the gut was washed with an aqueous buffer solution $(30 \mathrm{ml})$ using a pump (Masterflex ${ }^{\circledR}$ digital console L/S pump ${ }^{\circledR}$ drive; Core-Parmer Instrument Co., Barrington, IL, U.S.A.). The aqueous buffer solution consisted of $101.0 \mathrm{~mm} \mathrm{NaCl}$, $20.1 \mathrm{mM} \mathrm{Na}_{2} \mathrm{HPO}_{4} \cdot 12 \mathrm{H}_{2} \mathrm{O}$, and $47.0 \mathrm{~mm} \mathrm{KH} \mathrm{PO}_{4}(\mathrm{pH} 6.4)$. In order to evaluate intestinal absorption of mizoribine under $\mathrm{Na}^{+}$-free condition, $\mathrm{NaCl}$ and $\mathrm{Na}_{2} \mathrm{HPO}_{4} \cdot 12 \mathrm{H}_{2} \mathrm{O}$ in the aqueous buffer solution were replaced with choline chloride and $\mathrm{K}_{2} \mathrm{HPO}_{4}$, respectively. After the lumen of the gut was washed, a 15-cm-long intestinal loop under the opening of bile duct was prepared by ligation with a silk suture. The intestinal loop was put back into the body, and then the rats were kept still for $5 \mathrm{~min}$. A volume $(0.5 \mathrm{ml})$ of aqueous buffer solution containing mizoribine $(100 \mu \mathrm{g} / \mathrm{ml}=386 \mu \mathrm{M})$ and phenol red $(1 \mathrm{mg} / \mathrm{ml})$ was injected into the intestinal loop. After $40 \mathrm{~min}$, the content of an intestinal loop was collected with the fresh buffer solution. The collected solution was filtered using an Ultrafree ${ }^{\circledR}$-MC centrifugal filter unit (0.45 $\mu \mathrm{m}$, Millipore Co., Bedford, MA, U.S.A.) by centrifugation at $12000 \mathrm{~g}$ for $3 \mathrm{~min}$, and stored at $-30{ }^{\circ} \mathrm{C}$ until assay.

The amount of mizoribine in the sample solution was measured with a high-performance liquid chromatography (HPLC) method. A 50- $\mu$ l aliquot of the sample was injected into a HPLC system. The column was Develosil ${ }^{\mathrm{TM}}$ RPAqueous $(4.6 \mathrm{~mm}$ i.d. $\times 250 \mathrm{~mm}, 5 \mu \mathrm{m}$, Nomura Chemical Co., Ltd., Japan). Mizoribine was eluted using a gradient of the mobile phase A $(50 \mathrm{~mm}$ ammonium acetate adjusted to $\mathrm{pH}$ 5.6 with acetic acid), and the mobile phase B containing $80 \%$ $50 \mathrm{~mm}$ ammonium acetate $(\mathrm{pH} 5.6)$ and $20 \%$ acetonitrile $(\mathrm{v} / \mathrm{v})$. The gradient elution of mobile phase B was $0 \%$ in 0 $8 \mathrm{~min}, 5 \%$ for $8-12 \mathrm{~min}, 100 \%$ for $12-17 \mathrm{~min}$, and $0 \%$ for $17-35 \mathrm{~min}$. The flow rate was $0.9 \mathrm{ml} / \mathrm{min}$, and the column temperature was $40^{\circ} \mathrm{C}$. The peaks were monitored at $280 \mathrm{~nm}$.

Uptake of Mizoribine in LS180 Cells The cellular uptake of $\left[{ }^{14} \mathrm{C}\right]$ mizoribine was examined using LS180 cells grown on plastic dishes of multiwell plates. The composition of the incubation medium was as follows: $125 \mathrm{~mm} \mathrm{NaCl}$, $4.8 \mathrm{~mm} \mathrm{KCl}, 5.6 \mathrm{~mm}$ D-glucose, $1.2 \mathrm{~mm} \mathrm{CaCl}_{2}, 1.2 \mathrm{~mm}$ $\mathrm{MgSO}_{4} \cdot 7 \mathrm{H}_{2} \mathrm{O}, 25 \mathrm{~mm}$ 2-[4-(2-hydroxyethyl)-1-piperazinyl]ethanesulfonic acid (HEPES), and $400 \mu \mathrm{M}$ unlabeled mizoribine $(\mathrm{pH}$ 7.4). The cells were first pre-incubated for
$60 \mathrm{~min}$ at $37^{\circ} \mathrm{C}$ with $2 \mathrm{ml}$ of incubation medium. The incubation medium was replaced with $500 \mu \mathrm{l}$ of fresh incubation medium $10 \mathrm{~min}$ before addition of $\left[{ }^{14} \mathrm{C}\right]$ mizoribine $(0.2 \mu \mathrm{Ci}$ / well). After the cells were incubated with $\left[{ }^{14} \mathrm{C}\right]$ mizoribine for 5-60 min, they were immediately washed with ice-cold phosphate buffer, and collected. To evaluate efflux of mizoribine from the cells, the incubation medium was replaced with $\left[{ }^{14} \mathrm{C}\right]$ mizoribine-free incubation medium $30 \mathrm{~min}$ after addition of $\left[{ }^{14} \mathrm{C}\right]$ mizoribine, and then the cells were incubated for another $15-30 \mathrm{~min}$. The amount of $\left[{ }^{14} \mathrm{C}\right] \mathrm{mizori}-$ bine in the cells were determined using a liquid scintillation counter. To estimate extracellular trapping of mizoribine, the amount of $\left[{ }^{3} \mathrm{H}\right]$ mannitol in the cells was also determined. ${ }^{14)}$

The cellular uptake of mizoribine analyzed in a model-dependent manner using NONMEM software running on a mainframe UNIX machine at the Kyoto University Data Processing Center, as described previously. ${ }^{14,15)}$ The following mass balance equations were prepared for the pharmacokinetic analysis:

$$
\begin{aligned}
& \frac{d X_{\mathrm{C}}}{d t}=\frac{C L_{\mathrm{M} \rightarrow \mathrm{C}}}{V_{\mathrm{M}}} \cdot X_{\mathrm{M}}-\frac{C L_{\mathrm{C} \rightarrow \mathrm{M}}}{V_{\mathrm{C}}} \cdot X_{\mathrm{C}} \\
& \frac{d X_{\mathrm{C}}}{d t}=\frac{C L_{\mathrm{M} \rightarrow \mathrm{C}}}{V_{\mathrm{M}}} \cdot X_{\mathrm{M}}-\frac{C L_{\mathrm{C} \rightarrow \mathrm{M}}}{V_{\mathrm{C}}} \cdot X_{\mathrm{C}}
\end{aligned}
$$

where $X_{\mathrm{M}}$ and $X_{\mathrm{C}}$ are the amount of mizoribine in the incubation medium and the cells determined at time $t$, respectively. $V_{\mathrm{M}}$ indicates the volume of the incubation medium $(500 \mu \mathrm{l})$. $V_{\mathrm{C}}$ indicates the cell volume $\left(2.62 \mu \mathrm{l} / \mathrm{cm}^{2}\right)$, measured with sulfanilamide as described previously. ${ }^{11,12)}$ The influx and efflux clearance of mizoribine was designated as $C L_{\mathrm{M} \rightarrow \mathrm{C}}$ and $C L_{\mathrm{C} \rightarrow \mathrm{M}}$, respectively.

In order to evaluate cellular uptake of $\left[{ }^{14} \mathrm{C}\right]$ mizoribine under the $\mathrm{Na}^{+}$-free condition, $\mathrm{NaCl}$ in the incubation medium was replaced with choline chloride. In addition, to evaluate the effect of structurally related compounds and NBMPR on cellular uptake of $\left[{ }^{14} \mathrm{C}\right]$ mizoribine, the incubation medium was replaced with $500 \mu \mathrm{l}$ of fresh incubation medium containing 5-50 mM structurally related compounds or $100 \mu \mathrm{M}$ NBMPR 5-10 min before addition of $\left[{ }^{14} \mathrm{C}\right]$ mizoribine. The cells were incubated with $\left[{ }^{14} \mathrm{C}\right]$ mizoribine for $5-45 \mathrm{~min}$, and the amounts of $\left[{ }^{14} \mathrm{C}\right]$ mizoribine in the samples were determined as described above.

Real-Time Polymerase Chain Reaction Assay of mRNA of Transporters in LS180 Cells Total RNA was isolated from LS180 cells using an RNeasy ${ }^{\circledR}$ Mini Kit, QIAshredder, and RNase-Free DNase Set (QIAGEN, Valencia, CA, U.S.A.) according to the manufacturer's instructions. Reverse transcription of extracted total RNA was performed using an Omniscript $^{\circledR}$ RT Kit (QIAGEN) and random hexamer (QIAGEN) according to the manufacturer's instructions. PCR was carried put on the MX3000P ${ }^{\circledR}$ QPCR System (Stratagene, La Jolla, CA, U.S.A.) using SYBR ${ }^{\circledR}$ Premix Ex Taq ${ }^{\mathrm{TM}}$ (TaKaRa, Shiga, Japan) according to the manufacturer's instructions. Primer sequences for CNT1, CNT2, ENT1, ENT2, multidrug resistance protein (MDR) 1, multidrug resistance-associated protein (MRP) 1, MRP2, MRP4, MRP5, breast cancer resistance protein (BCRP), and glyceraldehyde-3-phosphate dehydrogenase (GAPDH) have been reported elsewhere. ${ }^{12,16,18-20)}$ Cycling conditions were 1 cycle for $30 \mathrm{~s}$ at $95^{\circ} \mathrm{C}$, followed 
by 45 cycles of 5 -s denaturation at $95^{\circ} \mathrm{C}, 20$-s annealing at $60^{\circ} \mathrm{C}$, and 15 -s extension at $72^{\circ} \mathrm{C}$. The mRNA level of nucleoside and efflux transporters was normalized according to GAPDH mRNA level, and the ratio was presented using a common logarithm.

Data Analysis Values are expressed as the mean \pm S.E. Multiple comparisons were performed using Scheffe's test following one-way ANOVA provided that the variances of groups were similar. If this was not the case, a Scheffe-type test was applied following Kruskal-Wallis analysis. $p<0.05$ was considered to be statistically significant.

\section{RESULTS AND DISCUSSION}

Intestinal Absorption of Mizoribine in Rats We first evaluated the intestinal absorption of mizoribine in rats using an in situ closed loop method. The intestinal absorption of mizoribine was estimated by calculating percentage of the dose $(50 \mu \mathrm{g}$ at the concentration of $100 \mu \mathrm{g} / \mathrm{ml}=386 \mu \mathrm{M})$ of mizoribine disappeared from rat intestinal loops for $40 \mathrm{~min}$. Mizoribine was absorbed much faster than phenol red (a representative hydrophilic compound), and the absorption rate of mizoribine in the presence of $141 \mathrm{mM} \mathrm{Na}^{+}$was $64.2 \%$ of the dose (Fig. 1). In addition, absorption of mizoribine in the absence of $\mathrm{Na}^{+}(63.7 \%$ of the dose) was comparable to that in the presence of $141 \mathrm{~mm} \mathrm{Na}^{+}$(Fig. 1). These findings indicated that $\mathrm{Na}^{+}$-independent transporters are mainly responsible for the intestinal absorption of mizoribine in rats.

Okada et al. evaluated the intestinal absorption of mizoribine which was dissolved in $\mathrm{Na}^{+}$-free distilled water $(30 \mu \mathrm{g}$ at the concentration of $100 \mu \mathrm{g} / \mathrm{ml}){ }^{7)}$ They reported that the 30-min absorption of mizoribine in rat intestinal loop (about $6-9-\mathrm{cm}$ loop from the end of the pylorus) was $52.9 \%$ of the dose, and that inosine significantly decreased the absorption rate of the drug. ${ }^{7}{ }^{7}$ On the other hand, Mori et al. investigated the absorption of mizoribine dissolved in saline $(1 \mathrm{mg} / \mathrm{kg}$ at the concentration of $500 \mu \mathrm{g} / \mathrm{ml}){ }^{8)}$ They reported that the 60 min absorption of mizoribine in rat intestinal loop $(10-\mathrm{cm}$ loop from $5 \mathrm{~cm}$ below the bile duct opening) was about $45 \%$ of the dose, and that inosine, thymidine, and ribavirin significantly decreased the absorption rate of the drug. ${ }^{8)}$ The results in the present study seemed to be in line with those previous findings of Okada et al. and Mori et al. ${ }^{7,8)}$

Pharmacokinetic Analysis of Mizoribine Uptake in LS180 Cells To characterize the membrane transport of mizoribine in the intestine, we next evaluated the uptake of mizoribine in human intestinal epithelial LS180 cells grown on plastic dishes. The cellular uptake of mizoribine in the presence of extracellular $125 \mathrm{mM} \mathrm{Na}^{+}$was time-dependent; that is, the uptake of $\left[{ }^{14} \mathrm{C}\right]$ mizoribine increased rapidly, and reached approximately $0.56 \%$ of dose at $30 \mathrm{~min}$ (Fig. 2). In the case that the extracellular medium containing $\left[{ }^{14} \mathrm{C}\right] \mathrm{mi}$ zoribine was replaced with $\left[{ }^{14} \mathrm{C}\right]$ mizoribine-free incubation medium $30 \mathrm{~min}$ after the addition of radio-labeled drug, intracellular $\left[{ }^{14} \mathrm{C}\right]$ mizoribine moved rapidly into extracellular medium (Fig. 2). We performed the pharmacokinetic analysis of the data on cellular mizoribine accumulation using a 2compartment (cell and medium) model. The influx and efflux clearance of mizoribine were estimated to be 118 and $424 \mathrm{nl} / \mathrm{min} / \mathrm{cm}^{2}$, respectively. The finding indicated that influx of mizoribine was not greater than efflux of the drug in

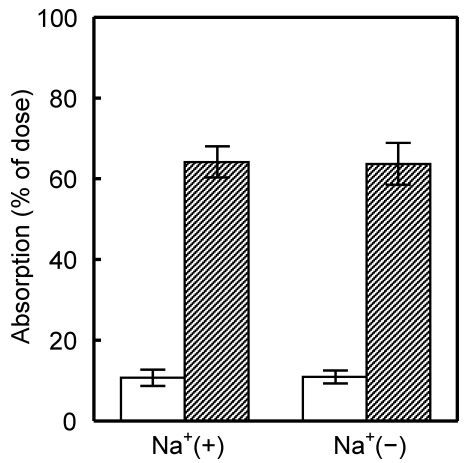

Fig. 1. Intestinal Absorption of Mizoribine for $40 \mathrm{~min}$ in Rats

Mizoribine solution $(100 \mu \mathrm{g} / \mathrm{ml})$ was injected into rat intestinal closed loop. Open and hatched columns represent 40-min absorption of phenol red and mizoribine, respectively. Each column represents the mean \pm S.E. for 7 rats.

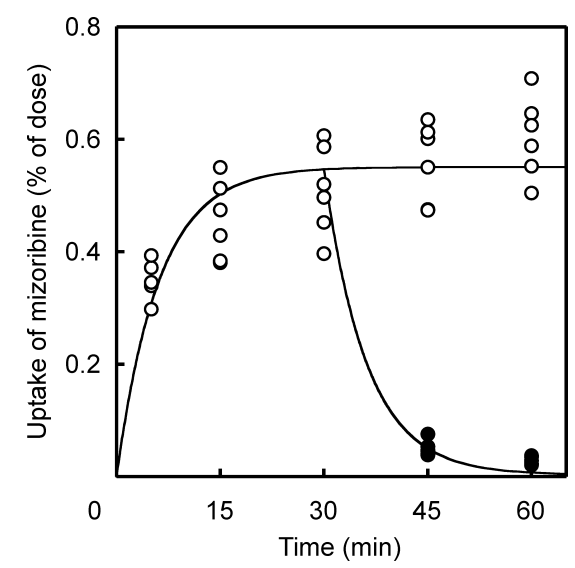

Fig. 2. Time Course of $400 \mu \mathrm{M}$ Mizoribine (Containing $31.0 \mu \mathrm{M}\left[{ }^{14} \mathrm{C}\right] \mathrm{Mi}-$ zoribine) Uptake in LS180 Cells in the Presence of $\mathrm{Na}^{+}$

Closed circles represent intracellular mizoribine after the incubation medium was replaced with $\left[{ }^{14} \mathrm{C}\right]$ mizoribine-free incubation medium at $30 \mathrm{~min}$ after the addition of the radio-labeled drug. Solid line represents a simulation curve obtained by pharmacokinetic analysis of mizoribine accumulation. Influx and efflux clearance was estimated to be 118 and $424 \mathrm{nl} / \mathrm{min} / \mathrm{cm}^{2}$, respectively.

\section{LS180 cells, even in the presence of $\mathrm{Na}^{+}$.}

Effect of Structurally Related Compounds on Uptake of Mizoribine in LS180 Cells We evaluated the inhibitory effect of structurally related compounds on the cellular uptake of mizoribine in the presence of extracellular $125 \mathrm{~mm}$ $\mathrm{Na}^{+}$. Figure 3 shows the uptake of $400 \mu \mathrm{M}$ mizoribine for $45 \mathrm{~min}$ in the presence of $5-50 \mathrm{~mm}$ structurally related compounds. Unlabeled mizoribine at concentrations of 5 and $50 \mathrm{~mm}$ did not significantly inhibit the apparent uptake of $\left[{ }^{14} \mathrm{C}\right]$ mizoribine (Fig. 3). On the other hand, ribavirin inhibited the uptake of $\left[{ }^{14} \mathrm{C}\right]$ mizoribine with increasing concentrations (from 5 to $50 \mathrm{~mm}$ ), although the inhibitory effects of 5 $\mathrm{mm}$ ribavirin were not statistically significant (Fig. 3). The inhibitory effects of 5 and $50 \mathrm{~mm}$ inosine on the uptake of $\left[{ }^{14} \mathrm{C}\right]$ mizoribine were stronger than that of $50 \mathrm{~mm}$ ribavirin. These findings indicated that specific nucleoside transporters are involved in the uptake of mizoribine in LS180 cells.

Effect of $\mathrm{Na}^{+}$and NBMPR on Uptake of Mizoribine in LS180 Cells We further investigated the initial (5-min) uptake of mizoribine to characterize the influx transporter of the drug in LS180 cells. Figure 4 shows the uptake of $400 \mu \mathrm{M}$ mizoribine for $5 \mathrm{~min}$ in the presence and absence of extracellular $\mathrm{Na}^{+}$. The removal of extracellular $\mathrm{Na}^{+}$significantly de- 


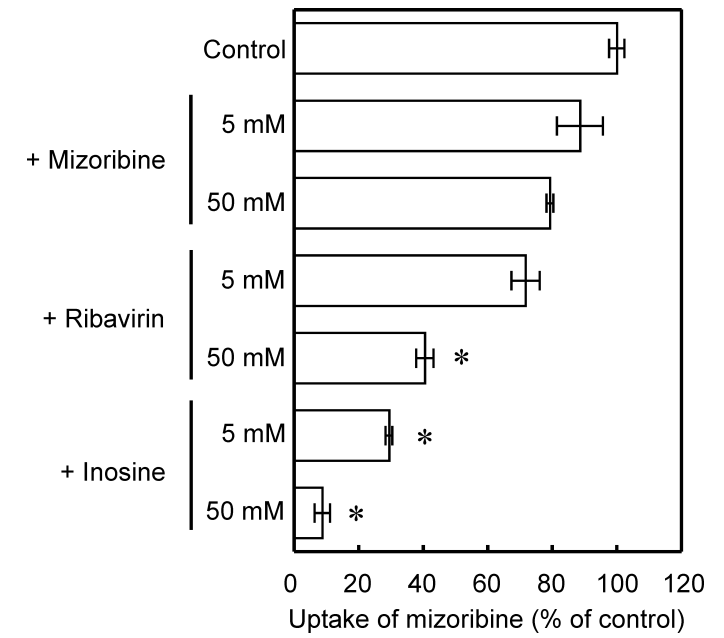

Fig. 3. Effect of Structurally Related Compounds on Uptake of $400 \mu \mathrm{M}$ Mizoribine (Containing $31.0 \mu \mathrm{M}\left[{ }^{14} \mathrm{C}\right]$ Mizoribine) in LS180 Cells in the Presence of $\mathrm{Na}^{+}$

The cells were incubated with $\left[{ }^{14} \mathrm{C}\right]$ mizoribine for $45 \mathrm{~min}$ in the presence or absence of structurally related compounds. Each column represents the mean \pm S.E. for $5-11$ measurements. $* p<0.05$; significantly different from control.

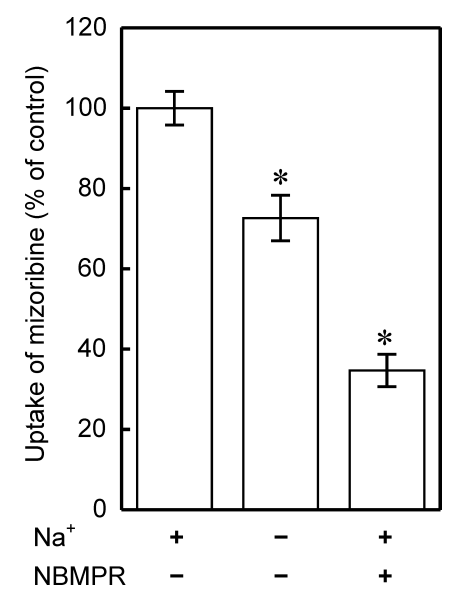

Fig. 4. Effect of $\mathrm{Na}^{+}$and NBMPR on Uptake of $400 \mu \mathrm{M}$ Mizoribine (Containing $31.0 \mu \mathrm{M}\left[{ }^{14} \mathrm{C}\right]$ Mizoribine) in LS180 Cells

The cells were incubated with $\left[{ }^{14} \mathrm{C}\right]$ mizoribine for $5 \mathrm{~min}$ in the presence or absence of $\mathrm{Na}^{+}$and NBMPR. Each column represents the mean \pm S.E. for 8 measurements. $* p<0.05$; significantly different from $\mathrm{Na}^{+}(+)$, NBMPR (-).

creased the uptake of mizoribine; however, the decrease in the uptake of mizoribine was only $27.3 \%$. Figure 4 also shows the effect of $100 \mu \mathrm{M}$ NBMPR, a specific inhibitor of ENTs, on the 5-min uptake of mizoribine in LS180 cells. The uptake of mizoribine in the presence of NBMPR was decreased to $34.7 \%$ of that without NBMPR (Fig. 4). These findings suggested that $\mathrm{Na}^{+}$-independent nucleoside transporters (probably ENTs) are largely responsible for the uptake of mizoribine in LS180 cells.

Expression of mRNA of Transporters in LS180 Cells We finally evaluated the expression of the mRNA of membrane transporters in LS180 cells. Figure 5 shows the mRNA expression level of nucleoside transporters (CNT1, CNT2, ENT1, and ENT2) in LS180 cells. The expression level of CNT1 mRNA was much lower than that of CNT2 mRNA, whereas the expression level of ENT1 and ENT2 mRNA was comparable to that of CNT2 mRNA (Fig. 5). Figure 5 also

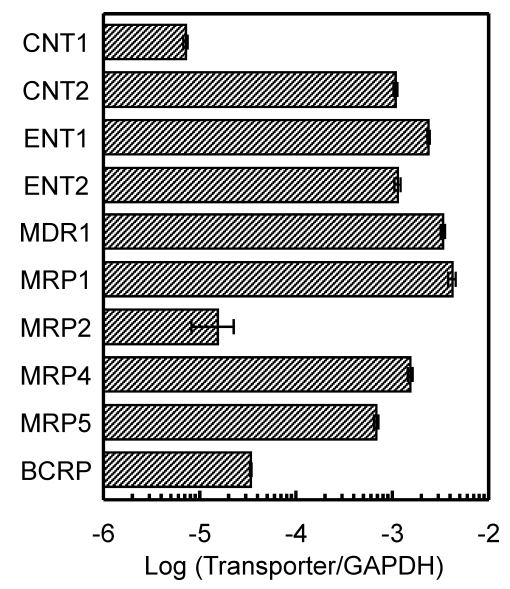

Fig. 5. Expression of the mRNA of Various Transporters in LS180 Cells Each column represents the mean \pm S.E. for 4 measurements.

shows the mRNA expression level of efflux transporters (MDR1, MRP1, MRP2, MRP4, MRP5, and BCRP) in LS180 cells. The expression level of MDR1, MRP1, MRP4, and MRP5 mRNA was much higher than that of MRP2 and BCRP mRNA (Fig. 5).

The preferred substrates for MDR1 are lipophilic compounds, such as cyclosporine and tacrolimus, whereas that for MRP1 are organic anions, e.g., drugs conjugated to glutathione $(\mathrm{GSH})$, glucuronate, or sulfate. ${ }^{21,22)}$ On the other hand, MRP4 and MRP5 transport nucleobase, nucleoside, and nucleotide analogs including cyclic nucleotides (cAMP and cGMP). ${ }^{22,23)}$ Reid et al. investigated the transport activity of MRP4 and MRP5 for antiviral and anticancer drugs, using MRP4- or MRP5-transfected human embryonic kidney (HEK) 293 cells. $^{23)}$ They reported that MRP4 transports 9(2-phosphonomethoxyethyl)adenine (PMEA), 9-(2-phosphonomethoxyethyl)guanine (PMEG), thioguanine, and cladribine, but that MRP5 transports PMEA and thioguanine, but not PMEG and cladribine. ${ }^{23)}$ It is still unclear whether MRP4 and/or MRP5 is involved in the membrane transport of mizoribine in LS180 cells. Further studies will be needed to clarify which influx/efflux transporters are responsible for brush-border membrane transport of mizoribine in the human intestine.

\section{CONCLUSION}

In the present study, we evaluated the contribution of $\mathrm{Na}^{+}$dependent and -independent nucleoside transporters to mizoribine absorption in the rat intestine and human intestinal epithelial LS180 cells. The present findings indicated that $\mathrm{Na}^{+}$-independent nucleoside transporters (probably ENTs) are largely responsible for the intestinal absorption of mizoribine in the rat intestine and LS180 cells. To our knowledge, this is the first report of involvement of $\mathrm{Na}^{+}$-independent transporters in the apical membrane transport of mizoribine in the intestine.

Acknowledgements This work was supported in part by Grants-in-Aid for Scientific Research from the Japan Society for the Promotion of Sciences (JSPS) and from the Ministry of Education, Culture, Sports, Science and Technology (MEXT) of Japan. 


\section{REFERENCES}

1) Takei S., Pediatr. Int., 44, 205-209 (2002).

2) Matsumoto K., Morino T., Hara T., Yano J., Tsujino M., Mizuno K., Yamamoto H., Jpn. J. Transplant, 17, S603-S614 (1982).

3) Honda M., Itoh H., Suzuki T., Hashimoto Y., Biol. Pharm. Bull., 29, $2460-2464$ (2006).

4) Gray J. H., Owen R. P., Giacomini K. M., Pflugers Arch., 447, 728734 (2004).

5) Podgorska M., Kocbuch K., Pawelczyk T., Acta Biochim. Pol., 52, $749-758$ (2005).

6) Govindarajan R., Bakken A. H., Hudkins K. L., Lai Y., Casado F. J., Pastor-Anglada M., Tse C. M., Hayashi J., Unadkat J. D., Am. J. Physiol. Regul. Integr. Comp. Physiol., 293, R1809-R1822 (2007).

7) Okada M., Suzuki K., Nakashima M., Nakanishi T., Fujioka N., Eur. J. Pharmacol., 531, 140-144 (2006).

8) Mori N., Yokooji T., Kamio Y., Murakami T., Eur. J. Pharmacol., 586, $52-58$ (2008).

9) Baldwin S. A., Beal P. R., Yao S. Y., King A. E., Cass C. E., Young J. D., Pflugers Arch., 447, 735-743 (2004).

10) Tom B. H., Rutzky L. P., Jakstys M. M., Oyasu R., Kaye C. I., Kahan B. D., In Vitro, 12, 180-191 (1976).

11) Li Q., Sai Y., Kato Y., Tamai I., Tsuji A., Pharm. Res., 20, 1119 1124 (2003).

12) Aiba T., Susa M., Fukumori S., Hashimoto Y., Drug Metab. Pharma- cokinet., 20, 268-274 (2005).

13) Fukumori S., Murata T., Taguchi M., Hashimoto Y., Drug Metab. Pharmacokinet., 22, 377-381 (2007).

14) Takaai M., Suzuki H., Ishida K., Tahara K., Hashimoto Y., Biol. Pharm. Bull., 30, 2167-2172 (2007).

15) Ishida K., Takaai M., Hashimoto Y., Biol. Pharm. Bull., 29, 522-526 (2006).

16) Molina-Arcas M., Bellosillo B., Casado F. J., Montserrat E., Gil J., Colomer D., Pastor-Anglada M., Blood, 101, 2328-2334 (2003).

17) Maubon N., Le Vee M., Fossati L., Audry M., Le Ferrec E., Bolze S., Fardel O., Fundam. Clin. Pharmacol., 21, 659-663 (2007).

18) Glaeser H., Bailey D. G., Dresser G. K., Gregor J. C., Schwarz U. I., McGrath J. S., Jolicoeur E., Lee W., Leake B. F., Tirona R. G., Kim R. B., Clin. Pharmacol. Ther, 81, 362-370 (2007).

19) Moriya Y., Nakamura T., Okamura N., Sakaeda T., Horinouchi M., Tamura T., Aoyama N., Kasuga M., Okumura K., Biol. Pharm. Bull., 29, 535-538 (2006).

20) Maubon N., Le Vee M., Fossati L., Audry M., Le Ferrec E., Bolze S., Fardel O., Fundam. Clin. Pharmacol., 21, 659-663 (2007).

21) Pal D., Mitra A. K., J. Neuroimmune Pharmacol., 1, 323-339 (2006).

22) Borst P., Evers R., Kool M., Wijnholds J., J. Natl. Cancer Inst., 92, 1295-1302 (2000).

23) Reid G., Wielinga P., Zelcer N., De Haas M., Van Deemter L., Wijnholds J., Balzarini J., Borst P., Mol. Pharmacol., 63, 1094-1103 (2003). 